\title{
Catalytical degradation of industrial dyes using biosynthesized selenium nanoparticles and evaluating its antimicrobial activities
}

\author{
Soumya Menon, Happy Agarwal and Venkat Kumar Shanmugam* (D)
}

\begin{abstract}
The release of textile dyes from the industries to the environment has become a significant health issue to humans and their surroundings, where a large number of dyes are wasted to the nearby water during the dyeing process. Therefore, the practice of the utilization of biosynthesized nanoparticles from numerous biological systems has been described, out of which plant material is considered the most appropriate method. The usage of plant material not only makes the procedure ecological but also their abundance makes it more cost-effective. The present study aims to biologically produce selenium nanoparticle using Mucuna pruriens seed powder and apply it in the degradation of dyes and removal of pathogenic bacterial cultures from pathogen-containing lake water using an optimum concentration of selenium nanoparticles. The production of selenium nanoparticles was characterized via visual coloration from colorless to brown solution which was checked using UV-Visible spectrophotometer, the crystalline structure was analyzed using X-ray diffraction, the morphology was analyzed with transmission electron microscopy, scanning electron microscopy, dynamic light scattering, which was in the range of 90-120 nm, with stable spherical monodisperse characteristics. The surface potential was checked using zeta potential, while the Atomic Force Microscopy gave information on the roughness of the nanoparticles, and the presence of $-\mathrm{OH},-\mathrm{COO}$, aromatic groups were confirmed with Fourier Transform Infrared spectroscopy. The biosynthesized nanoparticles were then analyzed for its environmental applications, like degradation of dyes from industrial wastes and checking its antimicrobial activities.
\end{abstract}

Keywords: Selenium nanoparticles, Green synthesis, Dye degradation, Textile azo dyes, Antimicrobial activities

\section{Introduction}

The recent developments in the field of nanoscience have garnered significant attention from various sectors since they can be utilized for detection, diagnostics, purifying industrial waste [1], role in energy production or utilization, catalysis [2], food technology [3] and therapeutics [4]. Nowadays water treatment has become one of the most worrying issues due to upsurge in the industrialization and population that result in contaminating the water

\footnotetext{
* Correspondence: venkatkumars@vit.ac.in

School of Bio-Sciences and Technology, Vellore Institute of Technology, Vellore 632014, India
}

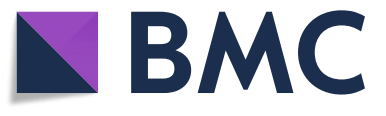

resources like the groundwater and reservoir. Therefore it is important to sanitize and reuse municipal and industrial wastewater. In the recent decade, the utilization of nanoparticles for wastewater treatment has picked up the extraordinary consideration because of its property being profoundly gainful as adsorbents and for utilizing for filtration reason [5].

Selenium is vital for proper nourishment in many living organisms, along with humans and other animals, but can be toxic in more significant quantities. Traditional supplements of selenium have a low level of absorption and expanded lethality. Consequently, to create novel materials

(c) The Author(s). 2021 Open Access This article is licensed under a Creative Commons Attribution 4.0 International License, which permits use, sharing, adaptation, distribution and reproduction in any medium or format, as long as you give appropriate credit to the original author(s) and the source, provide a link to the Creative Commons licence, and indicate if changes were made. The images or other third party material in this article are included in the article's Creative Commons licence, unless indicated otherwise in a credit line to the material. If material is not included in the article's Creative Commons licence and your intended use is not permitted by statutory regulation or exceeds the permitted use, you will need to obtain permission directly from the copyright holder. To view a copy of this licence, visit http://creativecommons.org/licenses/by/4.0/. 
as transporters of selenium compounds, which would raise the bioavailability of this component and permit its controlled release in the organism, has become a target to many researchers. It is a critical micronutrient and a metalloid (either metal or non-metal), and its supplementation gives various medical advantages. Selenium has several uses like decolorizing glass, making of pigment China Red, applications in laser printers, photocells, photocopiers, semiconductors, steels, and medicinal formulations. Selenium supplementation during fermentation with sugar beet molasses is found to be helpful in the production of fuels like bioethanol, which are clean and cost-effective in comparison to the alternate options [6-11].

Dyes are a collection of the synthetic organic complexes that are utilized as colorants in, textile, leather, pharmaceutical paper, cosmetic, food, and plastic industries [12]. Industrial effluents containing dyes are forming a severe environmental threat, as disposal of these effluents into natural water bodies often leads to environmental contamination, serving as a source of nonaesthetic pollution, eutrophication and thereby affecting the aquatic life. The removal or degradation of recalcitrant synthetic dyes is a crucial ecological problem and poses a challenge. Different methods like electrolysis, adsorption, oxidation, coagulation, active sludge biochemical procedures, membrane filtration, ozonization as well as bio-degradation have been used for the elimination of synthetic colorants from the wastewater. But, these recognized technologies are incapable to restrain the contaminant absorption to the preferred level with efficacy, a more efficient yet environment-friendly technique needs to be applied. The photocatalytic action of selenium nanoparticles (SeNPs) to the decolorization of sunset yellow azo-dye and its activity against human cancers has been established in the past already and thus this property was utilized to degrade dyes. In previous studies, it is evident that the photocatalytic analysis of biosynthesized SeNPs has proficiently degraded methylene blue under irradiation through sunlight. Therefore, they can discover applications in wastewater treatment plants and textile enterprises. Subsequently, the mixture of phyto-compounds and nanoparticles serves a functioning role in further pharmacological applications [13-16].

The fact that they demonstrate biological activity like the utilization as an antimicrobial agent inferable from their interaction with the proteins and different biomolecules present in microbes containing functional groups, for example, $-\mathrm{NH}, \mathrm{C}=\mathrm{O}, \mathrm{COO}$ and $\mathrm{C}-\mathrm{N}$. The antimicrobial activity can also be contributed due to the presence of phytochemicals surface decorated on the SeNPs like glycoside, alkaloids, flavonoids, steroids, tannin, proteins or tripenoids [17]. The advantages of green synthesis of nanoparticles are the single-step reaction that requires low energy for the initiation of the synthesis and has low incubation period when compared with microorganism based synthesis, it involves usage of fewer chemical which can be hazardous to the environment and is, therefore, cost-effective. The mechanism of nanoparticles synthesized from plant sources pursues the phases like (1) activation phase which involves the breakdown of precursor to elemental forms, (2) nucleation or growth phase of the elemental forms of $\mathrm{Se}_{0}$ (Ostwald ripening), and (3) termination or decline phase that defines the final morphology of the nanoparticles $[18,19]$. In our research, we formulated a way to synthesize SeNPs from seed samples in the laboratory on a small scale. In our study we aim to deal with two main aspects using SeNPs: a) Antimicrobial activity to destroy microbes and other harmful organisms in samples taken from water bodies; and b) Dye degradation. Se nanospheres have low toxicity and high biological potentiality this makes them harmless and suitable for addition in water and other natural samples which need to be obtained in a pure form [20].

\section{Materials and methods}

Sodium selenite, hydrogen peroxide was purchased from Hi-Media, India. Seeds of Mucuna pureins were purchased from a local drug store in Tamil Nadu. Escherichia coli was purchased from Microbial Type Culture Collection, India. The water sample was collected from the Vellore Institute of Technology (VIT) Lake, Vellore Institute of Technology, Vellore, Tamil Nadu.

\section{Preparation of $M$. pureins seed extract}

The seeds of $M$. pureins were dried under daylight and were crushed into coarse powder and stored at room temperature. $0.5 \mathrm{~g}$ of seeds in $50 \mathrm{~mL}$ of MilliQ water was boiled for $45 \mathrm{~min}$ at $60^{\circ} \mathrm{C}$. The extract was then cooled, filtered utilizing the Whatman filter paper and stored at $4{ }^{\circ} \mathrm{C}$ for further use.

\section{Synthesis of SeNPs}

SeNPs were synthesized using the precursor sodium selenite, a ratio of 9:1 was maintained, and $10 \mathrm{mM}$ of the precursor concentration and $1 \%$ of seed extract was supplemented. The solution was covered and was kept in the shaker at $150 \mathrm{rpm}$ at room temperature. The synthesized solution was purified using MilliQ water and $70 \%$ ethanol by centrifuging at $10,000 \mathrm{rpm}$ for $15 \mathrm{~min}$. The dried samples were procured by lyophilization and stored at room temperature in airtight containers for further purposes.

\section{Characterization of the biosynthesized SeNPs UV-visible spectroscopy}

UV-Vis spectroscopy was utilized to study the bioreduction of sodium selenite to SeNPs by analyzing the wavelength at which maximum absorbance peak was 
seen and to decide the time taken for the synthesis. The range was from 300 to $700 \mathrm{~nm}$. The phenomenon explained behind the working principle of UV-Vis is the surface plasmon resonance, which is an optical technique utilized for detecting molecular interactions [18].

\section{Fourier transform infrared spectroscopy (FTIR)}

FTIR spectroscopy is considered as an important characterization instrument to portray the structure of nanoparticles. Based on single vibrational modes of various particles, one can uncover its comprising components and its arrangements in their chemical bonds. The FTIR examination was done utilizing Shimadzu Spectroscopy (Model IR Affinity-1) with a wavenumber range of around $400-4000 \mathrm{~cm}^{-1}$, estimation of the infrared intensity versus the wavenumber gives data about the potential collaborations of the functional groups associated with the bio-reduction procedure [21].

\section{$X$-ray diffraction (XRD)}

XRD offers unmatched precision in the estimation of atomic separating and the X-ray diffractogram of nanomaterials gives an abundance of data from phase composition to crystallite size, from grid strain to crystallographic direction. The essential utilization of powder diffraction is to distinguish its components in the sample [22].

\section{Transmission electron microscopy (TEM)}

TEM is the perfect instrument for structural and chemical characterization at the nanoscale. Imaging, diffraction and microanalytical information are quickly produced and then combined to give detailed insights into the properties and behavior of nanostructured materials. It examines the dispersity, the roughness of the particle, in addition to the particle size and its morphology [23].

\section{Dynamic light scattering (DLS)}

DLS analysis portrays the transient structure of the molecule's Brownian motion in fluid suspension, which conveys basic data about the size of the particles and by estimating the transient structure rather than angular distribution, it can quantify particles in nanometers [24].

\section{Scanning electron microscopy (SEM)}

SEM is an electron magnifying instrument that examines the sample surface by filtering it with high energy beams of the electron. When the beam of electron strikes the surface of the sample, interacting with the atoms of the sample, secondary electrons are emitted, backscattered electrons and characteristic X-rays are produced that contains data about the sample's surface topography or its composition. SEM demonstrates three-dimensional images at numerous high amplifications which are nearly up to $\times 300,000$ ). We utilized ZEISS (EV018) Japan $15 \mathrm{Kv}$ for the examination of the biosynthesized SeNPs [25].

\section{Atomic force microscopy (AFM)}

AFM assists in analyzing singular or group of particles and three-dimensional images were produced. The AFM offers perception in three measurements. In the vertical or $\mathrm{z}$-axis, the resolution is constrained by the vibration condition of the instrument: while in the $x-y$ axis, it is characterized by the distance across of tip used for examining. Programming based images prepared can produce quantitative data from individual nanoparticles and between groups of nanoparticles which gives information on the size data and other physical properties (for example, morphology and surface topography) can be estimated [26].

\section{Evaluation of antimicrobial activities of biosynthesised SeNPs \\ Minimal inhibition concentration (MIC)}

MIC of the nanoparticles was found to remove the pathogenic bacterial cultures from water, which was analyzed by the Spread Plate Technique. MIC estimates the lowest level of the compound that is needed to kill or inhibit the growth of bacterial cultures. The ability of the mixture to inhibit the growth of bacteria is based on the extent of its anti-bacterial property. For estimating MIC, a fresh bacterial culture of $E$. coli was prepared, and then concentrations of the SeNPs formed were made: (50, 250, $500 \mu \mathrm{g} \mathrm{mL}^{-1}$ ). These various sub concentrations were made in different test tubes; nutrient media and bacterial culture were added to it to find out the MIC. The multiple test tubes setups made are shown in Table 1. All the test tubes were incubated for $24 \mathrm{~h}$ on a shaker (150 rpm).

\section{Removal of pathogenic bacterial cultures}

The water samples were collected from VIT Lake and to each $100 \mathrm{~mL}$ of samples, an optimized dose of SeNPs was added. The samples were then collected aseptically and were then spread on the Nutrient Agar plates at

Table 1 Various test tubes made to find out the minimum inhibitory concentration

\begin{tabular}{ll}
\hline & Components \\
\hline Test 1 & $\begin{array}{l}50 \mu \mathrm{gL}^{-1} \text { Se NPs + Nutrient broth + Bacterial } \\
\text { culture }\end{array}$ \\
Test 2 & $\begin{array}{l}250 \mu \mathrm{gL}^{-1} \text { Se NPs + Nutrient broth + Bacterial } \\
\text { culture } \\
500 \mu \mathrm{mL}^{-1} \text { Se NPs + Nutrient broth + Bacterial } \\
\text { culture }\end{array}$ \\
Test 3 & $\begin{array}{l}\text { Nutrient broth + Bacterial culture + Antibiotic } \\
\text { (Streptomycin) }\end{array}$ \\
Positive control & Nutrient broth + Bacterial culture \\
\hline
\end{tabular}


various time intervals $(0-60 \mathrm{~min})$. The plates were then incubated for an interval of $24 \mathrm{~h}$ at $37^{\circ} \mathrm{C}$, and the plates were analyzed for the growth of bacterial colonies [27].

\section{Dye degradation using biosynthesised SeNPs}

Dyes are substances that intensify their interaction with surfaces or textures to give its characteristic color. Based on their electric charge, they are classified into cationic and anionic moieties. They are generally utilized in the manufacturing industries, leather tanning, textile, printing or cosmetic and the utilization of dyes causes contamination in numerous water bodies. Most dyes are destructive to aquatic life since they reduce the penetration of light.

Absorbance readings were taken at various time intervals at a wavelength of $464 \mathrm{~nm}$ when SeNPs were treated with multiple groups of Methylene Orange dye, for Coomassie Brilliant Blue, the absorbance was taken at $595 \mathrm{~nm}$ and as for Bromophenol Blue $\left(3^{\prime}, 3^{\prime \prime}, 5^{\prime}, 5^{\prime \prime}\right.$-tetrabromophenolsulfonphthalein, $\mathrm{BPB})$, the absorbance was taken at $610 \mathrm{~nm}$ and was compared with standard hydrogen peroxide, that is used as a conventional dye absorbent [28].

\section{Statistical analysis}

All the results were in triplicate and were expressed as mean \pm standard deviation (SD) for the bacterium cultures. The statistical significance between the groups was determined by the one-way ANOVA followed by a test for trial trend and $p$-value of $<0.05$ was considered to be statistically significant.

\section{Results and discussion}

\section{Visual coloration and UV-visible analysis}

With the addition of seed extract to the precursor, the color of the solution changed into dark brown that indicated the development of SeNPs as shown in Figs. 1 and 2. The occurrence of the color change of the solution is due to the principle of surface plasmon resonance of the SeNPs [29].

The $\mathrm{pH}$ plays an important role in the synthesis of nanoparticles. In the case of SeNPs, it was optimized by changing the $\mathrm{pH}$ which was described by the color change of the reaction mixture and by analyzing the maximum absorbance peak using a UV-Vis spectrophotometer. At pH 6 and below, no color change occurred. It indicates that acidic $\mathrm{pH}$ suppresses the nanoparticles synthesis. At $\mathrm{pH} 7$, no color change was observed, which meant that neutral $\mathrm{pH}$ does not favor the SeNP synthesis. At $\mathrm{pH} 8$ and 9, the dark brown color was observed after $5 \mathrm{~min}$ incubation which turned darker later; hence, $\mathrm{pH} 8$ was the selected $\mathrm{pH}$ for the synthesis of SeNPs. Above $\mathrm{pH}$ 9, no color change was observed, indicating highly alkaline $\mathrm{pH}$ not appropriate for the biosynthesis of nanoparticles. Also, no significant absorbance peak was observed using a spectrophotometer. The differences in the arising of color over the various $\mathrm{pH}$ could be due to the presence of different dissociated functional groups of $M$. pruriens that are involved in the biosynthesis procedure [27, 28].

Wavelength scan for the solution consisting of the $M$. pruriens along with the sodium selenite was completed in the range from 300 to $700 \mathrm{~nm}$. The characteristic peak was obtained at $319 \mathrm{~nm}$. Agrobacterium-mediated biosynthesis had a $\lambda$ max at about $300 \mathrm{~nm}$ observed by Kora and Rastogi [30], Klebsiella pneumonia synthesized SeNPs had the maximum absorbance at $280 \mathrm{~nm}$ by Fesharaki et al. [31], the peak around $261 \mathrm{~nm}$ was observed using Diospyros montana as reported by Kokila et al. [32]. The characteristic peak acquired after $8 \mathrm{~h}$ showed that the biosynthesis of SeNPs had occurred, the biosynthesis was recorded up to around $10 \mathrm{~h}$; but beyond this time there was a decrease in the peak due to the aggregation of nanoparticles. The broad peak obtained signifies for the spherical-shaped nanoparticles [27]. Lower wavelength is absorbed mainly by particles with smaller size [33].

\section{Electron microscopy}

SEM and TEM images show the morphology of the biosynthesized SeNPs using M. pruriens extract. The SEM images reveal that the obtained nanoparticles were spherical shape within a size range of about $100-110 \mathrm{~nm}$

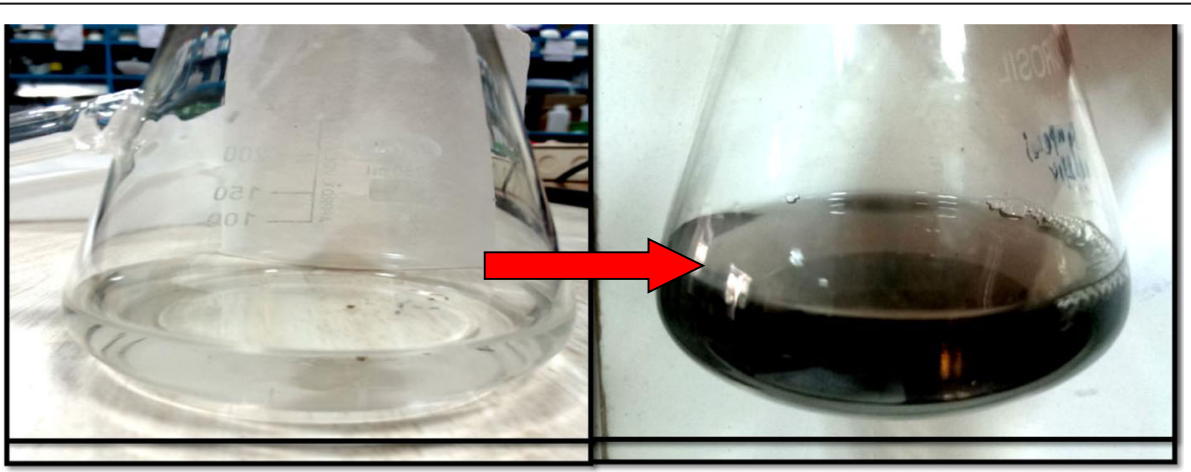

Fig. 1 The colour change was observed from colourless with the addition of extract and precursor to a dark brown solution when kept for incubation for $8 \mathrm{~h}$ 


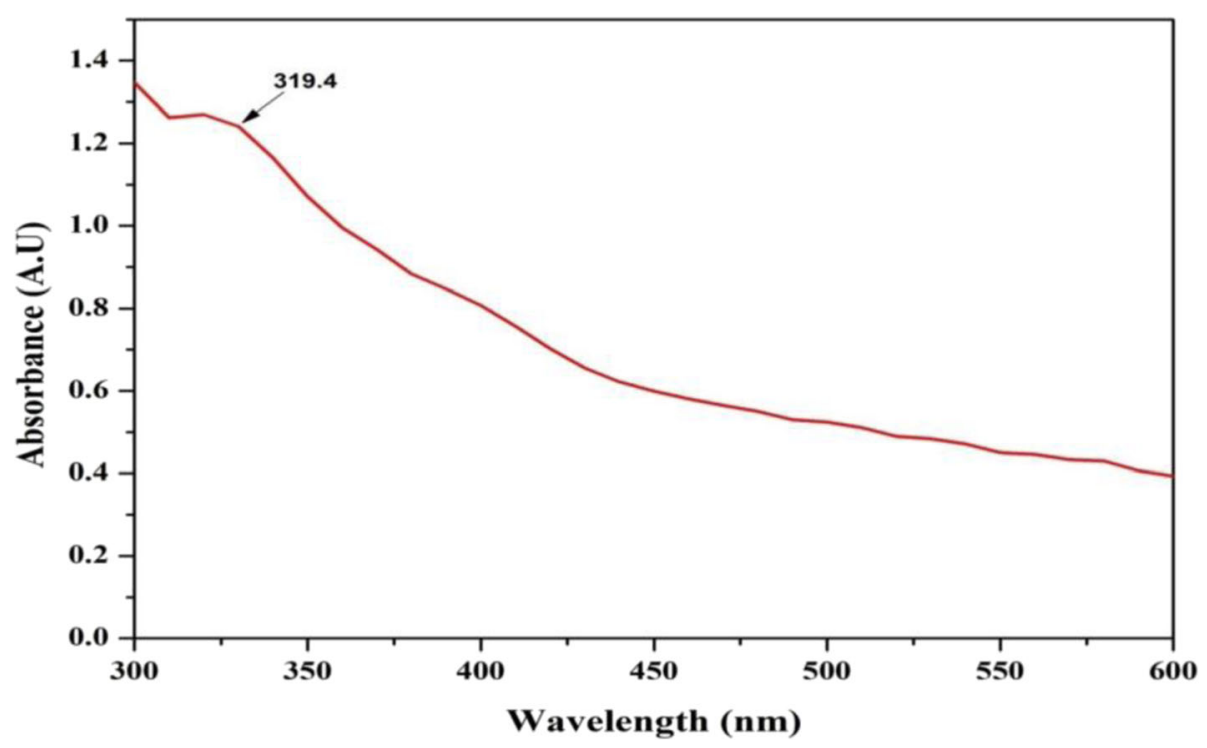

Fig. $2 \lambda_{\max }$ was examined using UV-Vis spectrophotometer of biosynthesised selenium nanoparticles

and were homogenously dispersed as shown in Figs. 3 and 4. The organic compounds or the biomolecules in the extract are responsible for the reduction and stabilization of the nanoparticles by preventing the aggregation of the nanoparticle [34]. Similar results were obtained for SeNPs synthesized using E. coli ATCC 35218 as reported by Kora and Rastogi [35], chitosan-coated SeNPs also gave uniform spherical morphology reported by Zeng et al. [36] and SeNPs coated with Clausena dentata plant leaf extract reported by Sowndarya et al. [37].

\section{FTIR analysis}

FTIR analysis was carried out to categorize the possible functional groups of the phytochemicals in the seed extract which are accountable for the bio-reduction of the nanoparticles [38]. The FTIR spectrum for the seed extract and SeNPs is demonstrated in Fig. 5; it displays a sharp absorption peak for seed extract at $32694 \mathrm{~cm}^{-1}$ which designates the occurrence of alcoholic groups, then for biosynthesized SeNPs there was a slight shift in the wavenumber at $3275 \mathrm{~cm}^{-1}$, other possible peaks for SeNPs were observed at $2912 \mathrm{~cm}^{-1}$ for aldehyde groups,

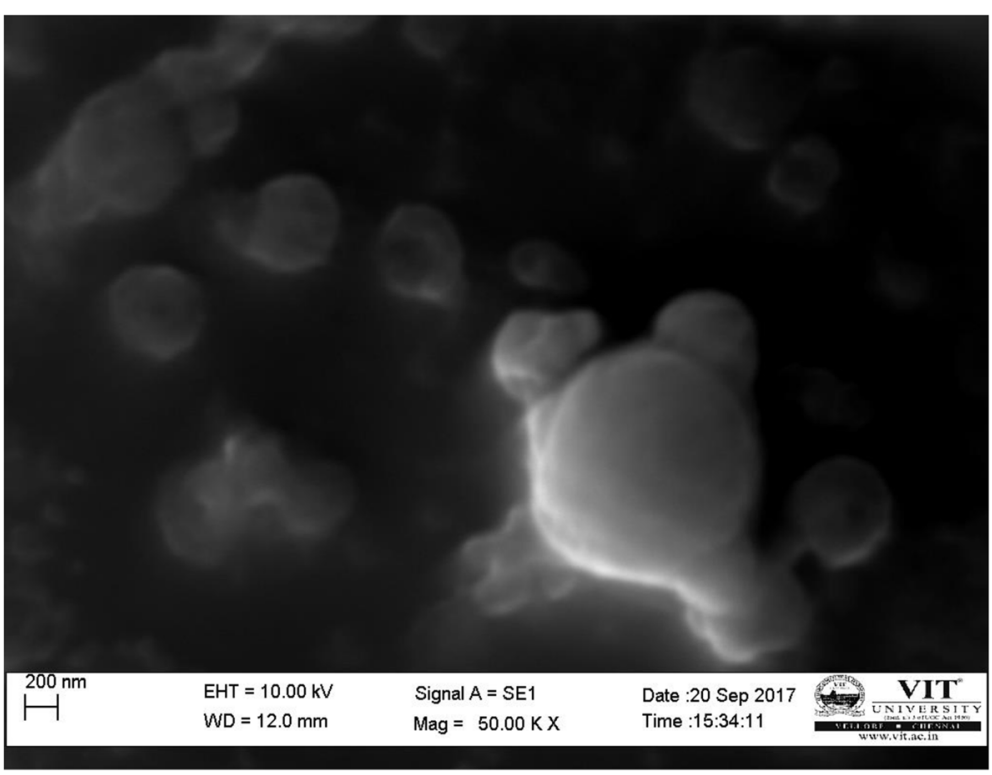

Fig. 3 SEM Analysis of the biosynthesised selenium nanoparticles 


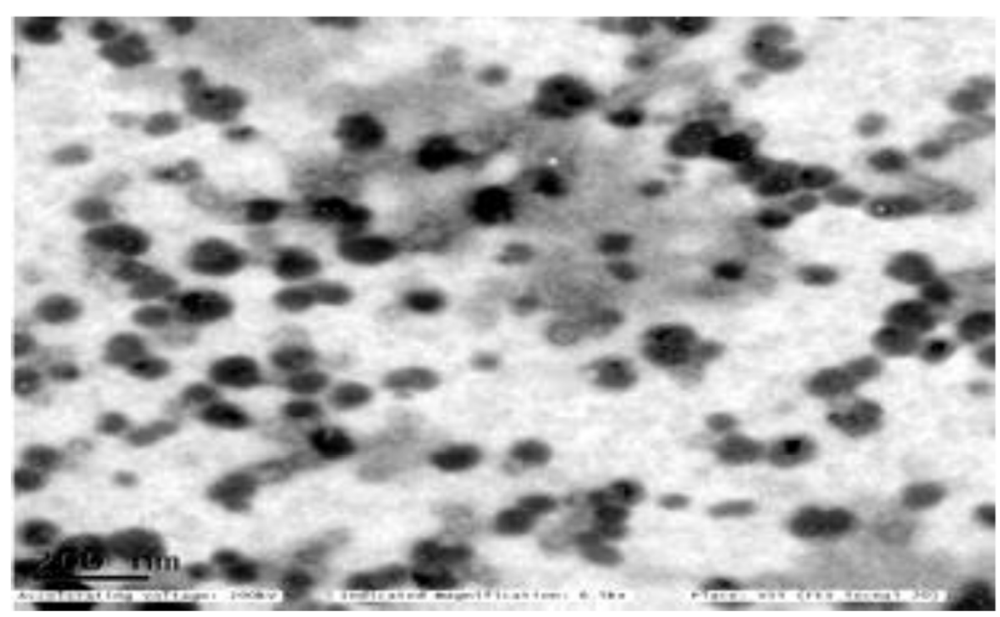

Fig. 4 TEM analysis of the biosynthesised selenium nanoparticles

C-N group for 2147, 1628 and $1603 \mathrm{~cm}^{-1}$ indicating the presence of $\mathrm{C}=\mathrm{O}$ stretching vibrations of carbonyls groups. A weak band was observed at $1385 \mathrm{~cm}^{-1}$ corresponding to the aliphatic bending group. Then at 1231 $\mathrm{cm}^{-1}$ alkyl ketone group is responsible, then at 1074 $\mathrm{cm}^{-1}$ alkyl amine groups are present and for the shifted wavenumber $976 \mathrm{~cm}^{-1}$ the $-\mathrm{CH}_{2}$ group vibrations are present. At $718 \mathrm{~cm}^{-1}$ falls for the $\mathrm{C}-\mathrm{H}$ group and at 521 $\mathrm{cm}^{-1}$ halogen groups are responsible. Similar results were observed by Alagesan and Venugopal [15]. The presence of the alkyl ketone group proves that flavonoids are present as one of the phytochemicals in the seed extract that contains variety of functional groups responsible for the bioreduction. The tautomeric transformation induces the release of hydrogen atoms which results in the conversion to a keto-form from its enol form. The alkyl amine groups indicates the presence of protein in the seed extract containing $\left(-\mathrm{NH}_{2}\right)$ helps in bioreduction and stabilization of the nanoparticles [39].

\section{DLS polydispersity index}

DLS was utilized for the examination of the homogenous size distribution and to analyze the purity of the biosynthesized SeNPs [40]. The DLS results (Fig. 6) provided the Z-value which was $110.3 \mathrm{~nm}$ that is the hydrodynamic radius of the nanoparticles. Also, it offered the polydispersity index value which was 0.3 , as it is less than 0.5 ; which indicates that the nanoparticles formed are homogeneous

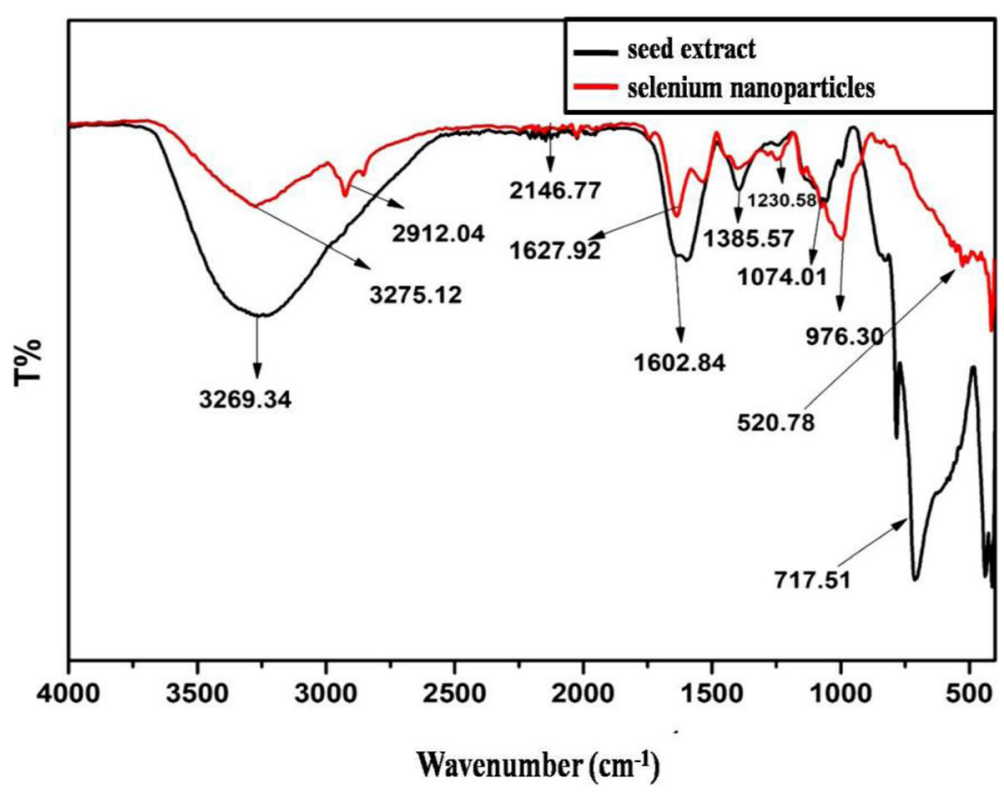

Fig. 5 FTIR analysis of the biosynthesised selenium nanoparticles 


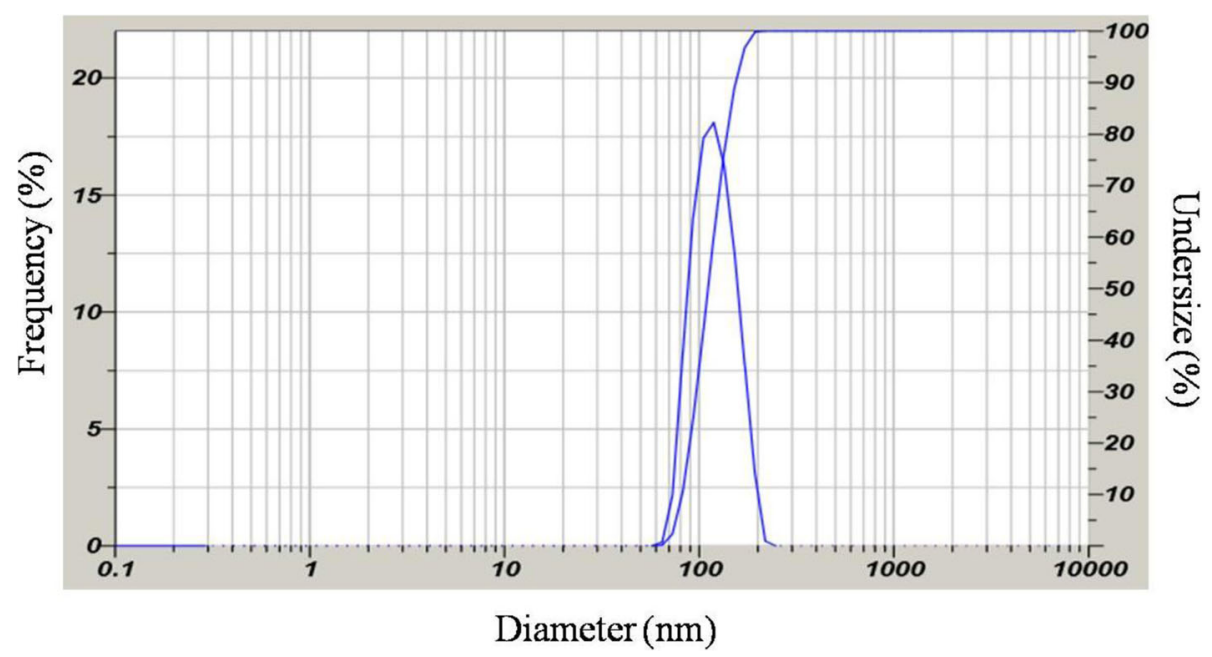

Fig. 6 DLS Analysis of biosynthesised selenium nanoparticles

and well dispersed., similar results were found in size range of $70-360 \mathrm{~nm}$ in a study by Avendano et al. [41], chitosan or carboxymethyl coated SeNPs also gave similar results by Chen et al. [42], and between 30 and $150 \mathrm{~nm}$ as reported by Sarkar et al. [43].

\section{AFM}

AFM was done to investigate the morphology, dispersity, porosity and surface topography [44] of the SeNPs. The white patch demonstrated in Fig. 7 portrays the spherical shape of the nanoparticles, while the 3D image gives information on the rough surface topography. From the data, it is interpreted that the average diameter size was around $120 \mathrm{~nm}$ with a height of $11 \mathrm{~nm}$. The AFM data gave information on the geometrical characteristics of the nanoparticles.

\section{XRD studies}

The crystalline characteristic nature of the biosynthesized SeNPs was evaluated using XRD as shown in Fig. 8. The obtained $2 \theta$ values which are characteristic for selenium elements were 23 and 31 at 100, 101 corresponding to crystallographic planes of trigonal selenium, while $2 \theta$ value of 26.4 corresponds to 220 crystallographic planes of $\beta$-monoclinic selenium $[11,45,46]$. Other peaks (110), (102), (201), (112), (202), (210) correspond to values like $41.8,44.6,56.9,62.9,65.2$ of selenium. Hence, they are in good agreement with the standard JCPDS data (JCPDS file no. 06-0362). Thereby, according to the Debye Scherrer equation [47], the calculated size was $98 \mathrm{~nm}$.

\section{Application of SeNPs in dye degradation process}

Dyes as well as their by-products are cancer-causing agents or are mutagenic to various living beings and can cause toxic effects to the kidney, liver, brain and central nervous system in individuals [48]. Dye degradation is a methodology where the massive size color atoms are burst down synthetically into smaller size particles. The subsequent by-products are carbon dioxide, water and mineral that imparts the dye color [49]. Methyl Orange is a $\mathrm{pH}$ indicator and utilized in titration due to its distinct color at various $\mathrm{pH}$ values [50]. BPB is utilized as a pH indicator or dye [51]. Coomassie Brilliant Blue is used in the textile industries and as a staining proteindye [52].

In the case of Methyl Orange, BPB and Coomassie Brilliant Blue, the absorbance readings, with the setups followed demonstrated in Table 2, were taken using a $\mathrm{UV}$-Vis spectrophotometer at $3 \mathrm{~h}$ time interval at 464 $\mathrm{nm}$ as shown in Fig. 9.

As far as the observations are concerned, Setup 4 (Dye $+\mathrm{H}_{2} \mathrm{O}_{2}+\mathrm{SeNPs}$ ) proved to be the most efficient in the case of all the dyes. It indicates that SeNPs are involved in the better degradation of dye as compared to conventional hydrogen peroxide which requires a catalyst to act. It could also be considered that SeNPs act as the catalyst for hydrogen peroxide and together they both help in efficient dye degradation. But the various dyes used as the model dyes in the experiment took different time to reach the constant concentration after the degradation. It is because the structures of all the dyes are different [53]. Methyl Orange has the simplest structure out of the others, hence took the least time to get degraded and achieve its constant concentration. Coomassie Brilliant Blue has the most complex structure; therefore, the time required to get dye degraded is more than those of Methyl Orange and BPB. The mechanism of catalytic degradation is represented through Eqs. (1), (2) and (3) 

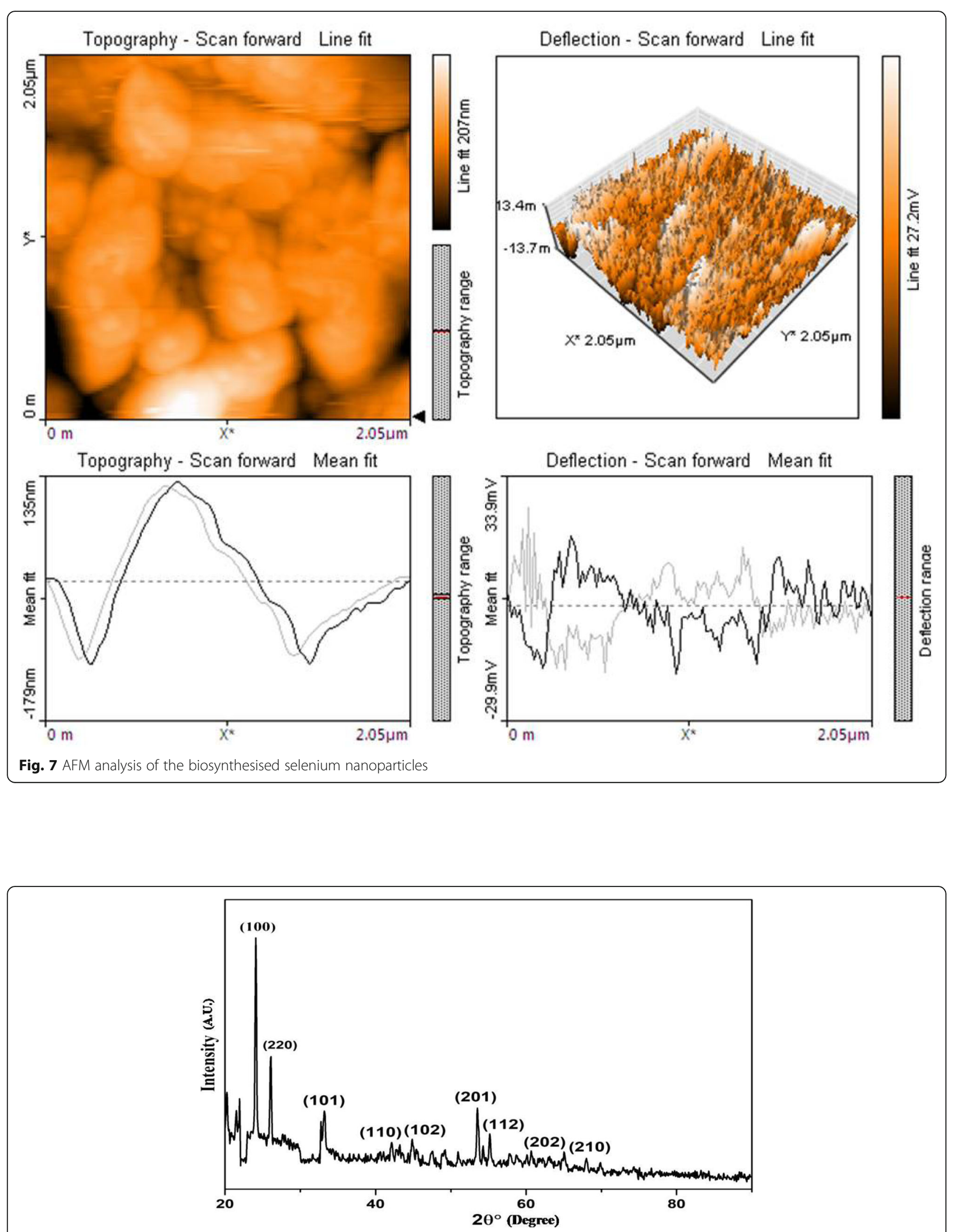

Fig. 8 XRD analysis of biosynthesised selenium nanoparticles 
Table 2 The setups for catalytic dye degradation

\begin{tabular}{llccc}
\hline Set up & $\begin{array}{l}\text { Methyl Orange/Bromophenol Blue/ } \\
\text { Coomassie Brilliant Blue }(1 \mathrm{~mL})\end{array}$ & Water $(1 \mathrm{~mL})$ & $\mathrm{H}_{2} \mathrm{O}_{2}(1 \mathrm{~mL})$ & Selenium nanoparticles $(1 \mathrm{~mL})$ \\
\hline 1 & + & + & - & - \\
2 & + & + & + & + \\
3 & + & + & - & + \\
4 & + & - & + & + \\
\hline
\end{tabular}

\section{a)}

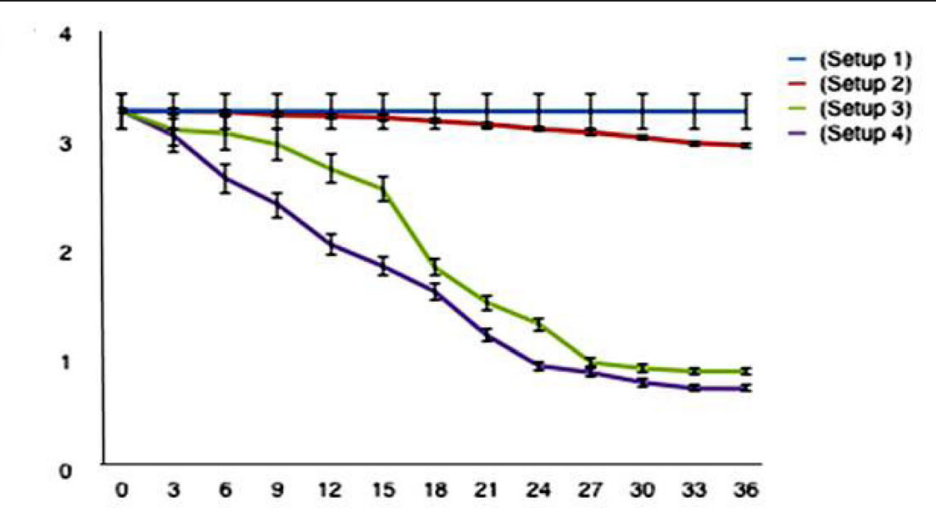

b)
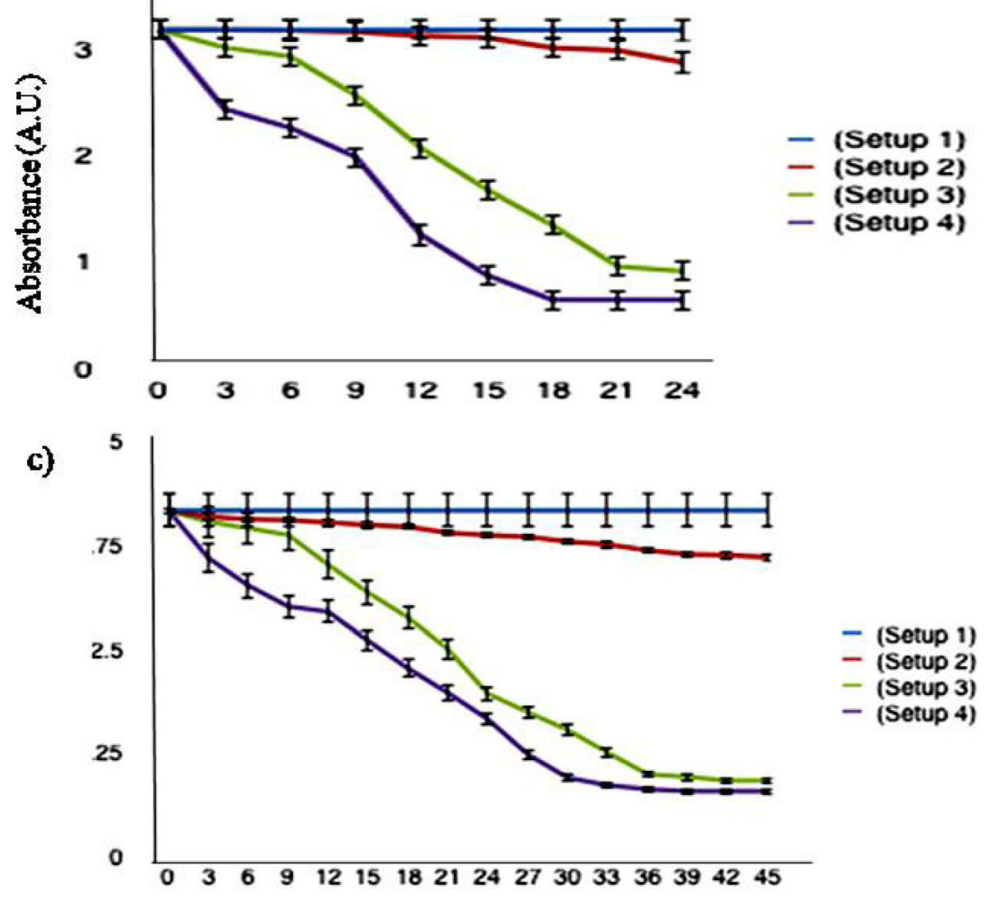

Time (h)

Fig. 9 Absorbance graph to evaluate the dye degradation of (a) Bromophenol Blue (b) Methyl Orange and (c) Coomassie Brilliant Blue for various setups 


$$
\begin{aligned}
& \mathrm{H}_{2} \mathrm{O}_{2}+\mathrm{e}=\mathrm{OH}^{-}+\mathrm{OH} \rightarrow \\
& \text { Dye (Methyl Orange, Coomassie Brilliant Blue and BPB) } \\
& \quad+\text { SeNPs } *=\text { SeNPs }^{-}+\text {dye }^{+} \rightarrow \\
& \\
& \quad+\mathrm{CO}_{2}+\mathrm{H}_{2} \mathrm{O} \rightarrow
\end{aligned}
$$

\section{Application of SeNPs in removing bacteria from the water} MIC analysis was performed and similar results were observed [54] and the MIC value was added to lake water and was spread onto the Nutrient Agar Plate. It is very clear from the spread plates that at time $t=0 \mathrm{~min}$, maximum bacterial growth is observed, but at the time $t=$ $60 \mathrm{~min}$, the bacterial growth was minimum as shown in Figs. 10 and 11. Hence, SeNPs could be considered as the way of purifying the water by killing or inhibiting the growth of the pathogenic bacterial cultures. The production of safe drinking water is a significant obstacle in both developed and developing countries. The demand for better water quality management has led to the innovation of disinfectants; amongst these SeNPs can also be a part of it. Many nanoparticles have been used in the past years for water purification. Silver nanoparticles help remove pesticides and halogenated organics, Titania nanoparticles removes arsenic and also disinfect the water, Iron oxide nanoparticles remove heavy metals including arsenic, lead, chromium, zinc, copper and ceramic nanopowder also is used for disinfection of water [55-59].

\section{Conclusions}

The biosynthesis of SeNPs mediated through a green route using seed extract of $M$. pruriens at physiological conditions like room temperature, is a procedure which is simple, eco- friendly and highly efficient. The time intervals for the reaction with aqueous sodium selenite solution showed an increase in the absorbance with time and became constant giving a maximum absorbance at $319.4 \mathrm{~nm}$ after an incubation of $8 \mathrm{~h}$. The results from DLS, XRD, SEM and TEM suggested the biosynthesis SeNP to be spherical with a size of 95$110 \mathrm{~nm}$. FTIR indicates the presence of alcoholic groups with $\mathrm{C}=\mathrm{O}$ bonds and $\mathrm{C}-\mathrm{O}$ stretching of carboxylic groups. The synthesized nanoparticles exhibit dye degradation activity indicating that SeNPs are involved in better degradation of dye as compared to the conventional hydrogen peroxide which requires a catalyst to act. The synthesized SeNPs also shows

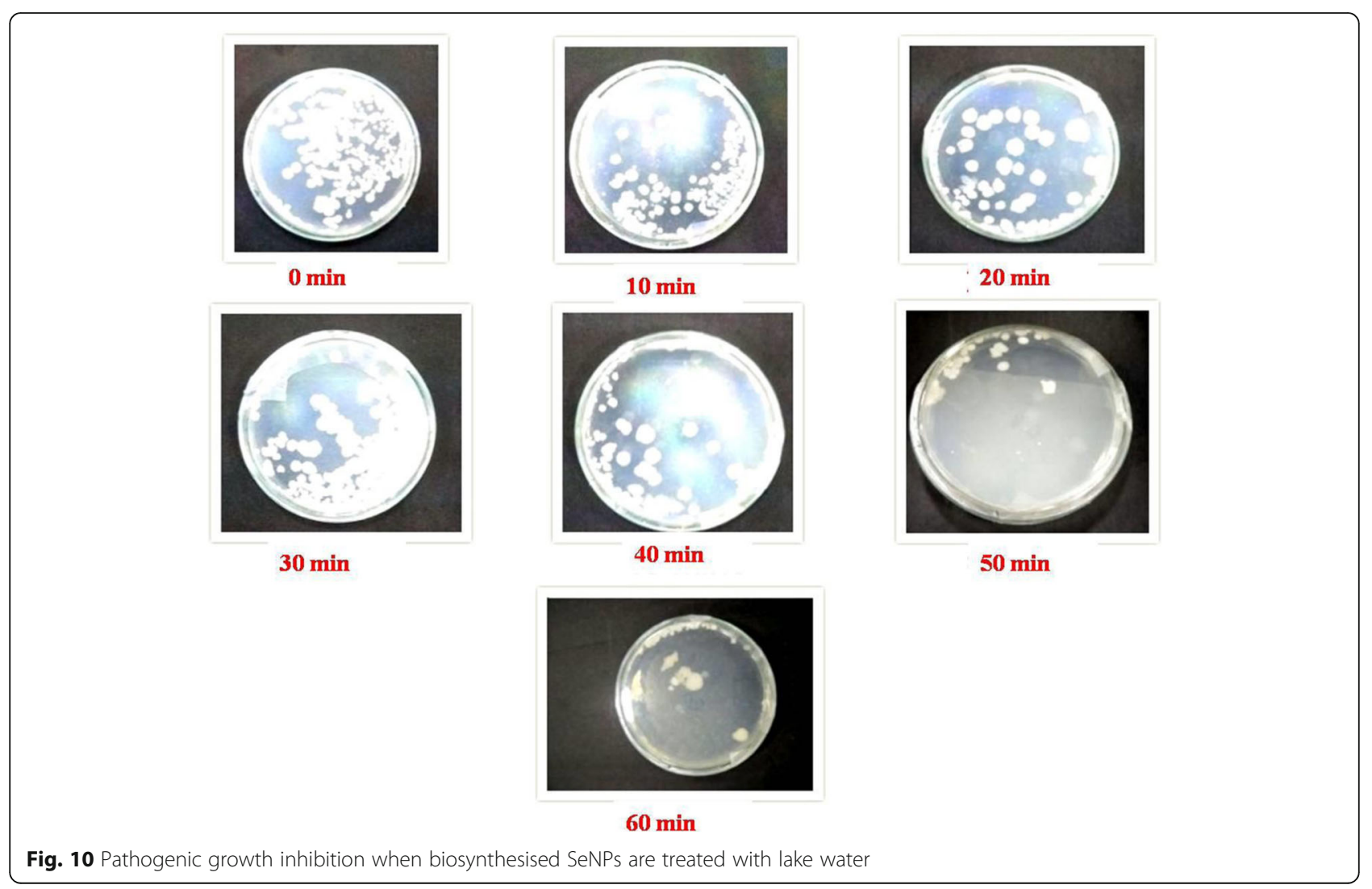




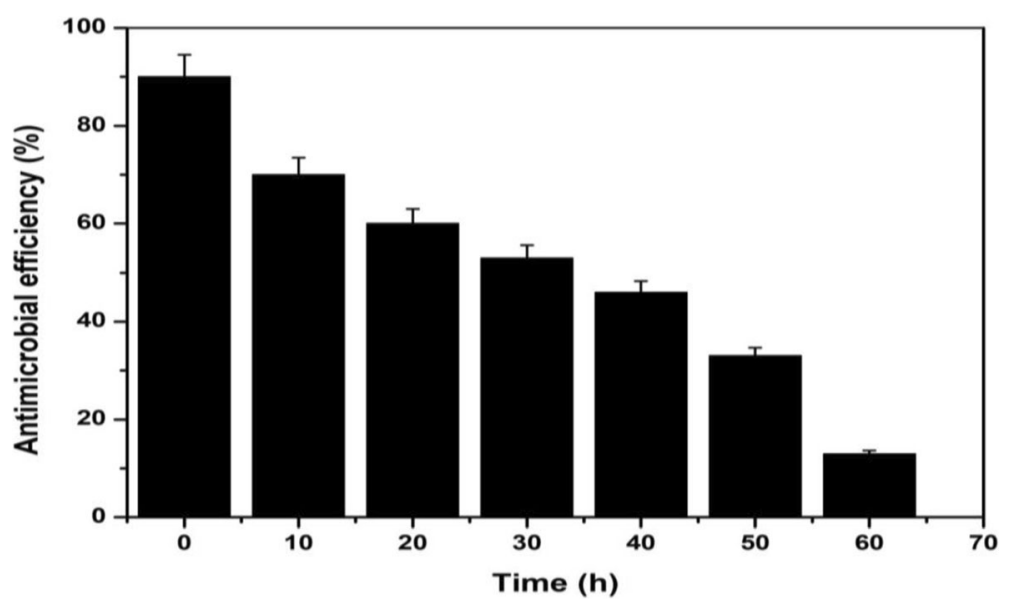

Fig. 11 Antimicrobial efficiency of biosynthesized SeNPs on removal of pathogens from lake water

pathogenic bacterial culture removal activity from an open-water source. The optimum concentration for removal of the pathogenic bacterial culture was found to be $250 \mu \mathrm{g} \mathrm{mL}-1$. The optimum time for the removal process was $60 \mathrm{~min}$. Consequently, it can be concluded that the biosynthesized SeNPs have an effective capacity in pathogenic bacterial culture removal and can be used for purification of contaminated water.

\section{Acknowledgments}

The authors would like to thank the Vellore Institute of Technology for all the resources and funding to proceed with the study.

\section{Declarations}

The authors certify that they have no affiliations with or involvement in any organization or entity with any financial interestor non-financial interest in the subject matter or materials discussed in this manuscript.

\section{Authors' contributions}

SM carried out the design of research, instrumental analysis interpretation of nanomaterials, and writing the manuscript. HA and VKS participated in the correction of the manuscript. All authors read and approved the final manuscript.

\section{Funding}

The funding was sanctioned by the Vellore Institute of Technology through seed grants.

\section{Availability of data and materials}

The datasets used and/or analyzed during the current study are available from the corresponding author on reasonable request.

\section{Competing interests}

The authors declare that they have no competing interests.

Received: 3 January 2020 Accepted: 9 November 2020 Published online: 07 January 2021

\section{References}

1. Sharma JK, Srivastava P, Ameen S, Akhtar MS, Sengupta SK, Singh G. Phytoconstituents assisted green synthesis of cerium oxide nanoparticles for thermal decomposition and dye remediation. Mater Res Bull. 2017;91:98-107.
2. Gangadoo S, Stanley D, Hughes RJ, Moore RJ, Chapman J. The synthesis and characterisation of highly stable and reproducible selenium nanoparticles. Inorg Nano-Met Chem. 2017:47:1568-76.

3. Venkatasubbu GD, Baskar R, Anusuya T, Seshan CA, Chelliah R. Toxicity mechanism of titanium dioxide and zinc oxide nanoparticles against food pathogens. Colloid Surface B. 2016;148:600-6.

4. Menon S, Devi KSS, Santhiya R, Rajeshkumar S, Kumar SV. Selenium nanoparticles: a potent chemotherapeutic agent and an elucidation of its mechanism. Colloid Surface B. 2018;170:280-92.

5. Iravani S. Green synthesis of metal nanoparticles using plants. Green Chem. 2011;13:2638-50.

6. Flohe L, Andreesen JR, Brigelius-Flohe R, Maiorino M, Ursini F. Selenium, the element of the moon, in life on earth. IUBMB Life. 2000:49:411-20.

7. Abdulah R, Miyazaki K, Nakazawa M, Koyama H. Chemical forms of selenium for cancer prevention. J Trace Elem Med Bio. 2005;19:141-50.

8. Weekley $\mathrm{CM}$, Harris $\mathrm{HH}$. Which form is that? The importance of selenium speciation and metabolism in the prevention and treatment of disease. Chem Soc Rev. 2013;42:8870-94.

9. Chhabria S, Desai K. Selenium nanoparticles and their applications. In: Nalwa HS, editor. Encyclopedia of Nanoscience and Nanotechnology. Volume 20. Valencia: American Scientific Publishers. 2016:20:1-32.

10. Fernandez-Llamosas H, Castro L, Blazquez ML, Diaz E, Carmona M. Biosynthesis of selenium nanoparticles by Azoarcus sp. CIB. Microb Cell Fact. 2016;15:109.

11. Hassanien R, Abed-Elmageed AAI, Husein DZ. Eco-friendly approach to synthesize selenium nanoparticles: photocatalytic degradation of sunset yellow azo dye and anticancer activity. ChemistrySelect. 2019;4:9018-26.

12. Ananth A, Keerthika V, Rajan MR. Synthesis and characterization of nanoselenium and its antibacterial response on some important human pathogens. Curr Sci India. 2019;116:285-90.

13. Fathima JB, Pugazhendhi A, Oves M, Venis R. Synthesis of eco-friendly copper nanoparticles for augmentation of catalytic degradation of organic dyes. J Mol Liq. 2018;260:1-8.

14. Chaleshtori MZ, Hosseini M, Edalatpour R, Masud SMS, Chianelli RR. New porous titanium-niobium oxide for photocatalytic degradation of bromocresol green dye in aqueous solution. Mater Res Bull. 2013;48: $3961-7$.

15. Alagesan V, Venugopal S. Green synthesis of selenium nanoparticle using leaves extract of Withania somnifera and its biological applications and photocatalytic activities. Bionanoscience. 2019;9:105-16.

16. Essawy AA. Silver imprinted zinc oxide nanoparticles: green synthetic approach, characterization and efficient sunlight-induced photocatalytic water detoxification. J Clean Prod. 2018;183:1011-20.

17. Borhade SS. Antibacterial activity, phytochemical analysis of methanolic extract of Mucunapruriens. Int J Pharm Pharm Res. 2017;269-78.

18. Petruf K, Panak O, Valenta J, Nemec P. Tuning of photoluminescence colour in zinc oxide nanoparticles via lithium doping. Ceram Int. 2017:43:5223-8. 
19. Malarkodi C, Rajeshkumar S, Paulkumar K, Vanaja M, Gnanajobitha G, Annadurai G. Biosynthesis and antimicrobial activity of semiconductor nanoparticles against oral pathogens. Bioinorg Chem Appl. 2014;2014:347167.

20. Tran PA, Webster TJ. Selenium nanoparticles inhibit Staphylococcus aureus growth. Int J Nanomed. 2011;6:1553-8.

21. Baudot C, Tan CM, Kong JC. FTIR spectroscopy as a tool for nano-material characterization. Infrared Phys Techn. 2010;53:434-8.

22. Sharma R, Bisen D, Shukla U, Sharma B. X-ray diffraction: a powerful method of characterizing nanomaterials. Recent Res Sci Tech. 2012;4:77-9.

23. Smith DJ. Characterization of nanomaterials using transmission electron microscopy. In: Kirkland Al, Haigh SJ Sarah JH, editors. Nanocharacterisation. 2nd ed. Cambridge: Royal Society of Chemistry; 2015. p. 1-29.

24. Tomaszewska E, Soliwoda K, Kadziola K, Tkacz-Szczesna B, Celichowski G, Cichomski M, et al. Detection limits of DLS and UV-Vis spectroscopy in characterization of polydisperse nanoparticles colloids. J Nanomater. 2013; 2013:313081.

25. Sun DD, Liu YN, Yu QQ, Zhou YH, Zhang R, Chen XJ, et al. The effects of luminescent ruthenium (II) polypyridyl functionalized selenium nanoparticles on bFGF-induced angiogenesis and AKT/ERK signaling. Biomaterials. 2013; 34:171-80.

26. Smitha KT, Anitha A, Furuike T, Tamura H, Nair SV, Jayakumar R. In vitro evaluation of paclitaxel loaded amorphous chitin nanoparticles for colon cancer drug delivery. Colloid Surface B. 2013;104:245-53.

27. Moustafa MT. Removal of pathogenic bacteria from wastewater using silver nanoparticles synthesized by two fungal species. Water Sci. 2017;31:164-76.

28. Usman M, Ahmed A, Yu B, Peng QH, Shen YQ, Cong HL. Photocatalytic potential of bio-engineered copper nanoparticles synthesized from Ficus carica extract for the degradation of toxic organic dye from waste water: growth mechanism and study of parameter affecting the degradation performance. Mater Res Bull. 2019;120:110583.

29. Mulvaney P. Surface plasmon spectroscopy of nanosized metal particles. Langmuir. 1996;12:788-800.

30. Kora AJ, Rastogi L. Biomimetic synthesis of selenium nanoparticles by Pseudomonas aeruginosa ATCC 27853: an approach for conversion of selenite. J Environ Manage. 2016;181:231-6.

31. Fesharaki PJ, Nazari P, Shakibaie M, Rezaie S, Banoee M, Abdollahi M, et al. Biosynthesis of selenium nanoparticles using Klebsiella pneumoniae and their recovery by a simple sterilization process. Braz J Microbiol. 2010:41:461-6.

32. Kokila K, Elavarasan N, Sujatha V. Diospyros montana leaf extract-mediated synthesis of selenium nanoparticles and their biological applications. New J Chem. 2017:41:7481-90.

33. Cui DX, Yan CQ, Miao JQ, Zhang XY, Chen JR, Sun LQ, et al. Synthesis, characterization and antitumor properties of selenium nanoparticles coupling with ferulic acid. Mat Sci Eng C-Mater. 2018;90:104-12.

34. Suresh D, Nethravathi PC, Udayabhanu, Rajanaika H, Nagabhushana H, Sharma $\mathrm{SC}$. Green synthesis of multifunctional zinc oxide $(\mathrm{ZnO})$ nanoparticles using Cassia fistula plant extract and their photodegradative, antioxidant and antibacterial activities. Mat Sci Semicon Proc. 2015;31:446-54.

35. Kora AJ, Rastogi L. Bacteriogenic synthesis of selenium nanoparticles by Escherichia coli ATCC 35218 and its structural characterisation. IET Nanobiotechnol. 2017:11:179-84.

36. Zeng SQ, Ke Y, Liv YX, Shen YB, Zhang L, Li C, et al. Synthesis and antidiabetic properties of chitosan-stabilized selenium nanoparticles. Colloid Surface B. 2018;170:115-21.

37. Sowndarya P, Ramkumar G, Shivakumar MS. Green synthesis of selenium nanoparticles conjugated Clausena dentata plant leaf extract and their insecticidal potential against mosquito vectors. Artif Cell Nanomed B. 2017; 45:1490-1495

38. Estevez H, Garcia-Lidon JC, Luque-Garcia JL, Camara C. Effects of chitosanstabilized selenium nanoparticles on cell proliferation, apoptosis and cell cycle pattern in HepG2 cells: comparison with other selenospecies. Colloid Surface B. 2014;122:184-193.

39. Singh J, Dutta T, Kim KH, Rawat M, Samddar P, Kumar P. "Green' synthesis of metals and their oxide nanoparticles: applications for environmental remediation. J Nanobiotechnol. 2018;16:84.

40. Gupta U, Sharma S, Khan I, Gothwal A, Sharma AK, Singh Y, et al. Enhanced apoptotic and anticancer potential of paclitaxel loaded biodegradable nanoparticles based on chitosan. Int J Biol Macromol. 2017;98:810-9.

41. Avendano R, Chaves N, Fuentes P, Sanchez E, Jimenez Jl, Chavarria M. Production of selenium nanoparticles in Pseudomonas putida KT2440. Sc Rep-UK. 2016;6:37155.
42. Chen WW, Li YF, Yang S, Yue L, Jiang QX, Xia WS. Synthesis and antioxidant properties of chitosan and carboxymethyl chitosan-stabilized selenium nanoparticles. Carbohyd Polym. 2015;132:574-81.

43. Sarkar J, Dey P, Saha S, Acharya K. Mycosynthesis of selenium nanoparticles. Micro Nano Lett. 2011;6:599-602.

44. Yuvakkumar R, Suresh J, Nathanael AJ, Sundrarajan M, Hong SI. Novel green synthetic strategy to prepare $\mathrm{ZnO}$ nanocrystals using rambutan (Nephelium lappaceum L.) peel extract and its antibacterial applications. Mat Sci Eng CMater. 2014;41:17-27.

45. Kannan S, Mohanraj K, Prabhu K, Barathan S, Sivakumar G. Synthesis of selenium nanorods with assistance of biomolecule. B Mater Sci. 2014:37:1631-5.

46. Jain R, Seder-Colomina M, Jordan N, Dessi P, Cosmidis J, van Hullebusch ED, et al. Entrapped elemental selenium nanoparticles affect physicochemical properties of selenium fed activated sludge. J Hazard Mater. 2015;295:193-200.

47. Kapur M, Soni K, Kohli K. Green synthesis of selenium nanoparticles from broccoli, characterization, application and toxicity. Adv Tech Biol Med. 2017;5:198.

48. Khade GV, Suwarnkar MB, Gavade NL, Garadkar KM. Green synthesis of $\mathrm{TiO}_{2}$ and its photocatalytic activity. J Mater Sci-Mater El. 2015;26:3309-15.

49. Ali J, Irshad R, Li BS, Tahir K, Ahmad A, Shakeel M, et al. Synthesis and characterization of phytochemical fabricated zinc oxide nanoparticles with enhanced antibacterial and catalytic applications. J Photoch Photobio B. 2018;183:349-56.

50. Nava OJ, Soto-Robles CA, Gomez-Gutierrez CM, Vilchis-Nestor AR, CastroBeltran A, Olivas A, et al. Fruit peel extract mediated green synthesis of zinc oxide nanoparticles. J Mol Struct. 2017;1147:1-6.

51. Balaji S, Kumar MB. Facile green synthesis of zinc oxide nanoparticles by Eucalyptus globulus and their photocatalytic and antioxidant activity. Adv Powder Technol. 2017;28:785-97.

52. Krupa AND, Vimala R. Evaluation of tetraethoxysilane (TEOS) sol-gel coatings, modified with green synthesized zinc oxide nanoparticles for combating microfouling. Mat Sci Eng C-Mater. 2016;61:728-35.

53. Goutam SP, Saxena G, Singh V, Yadav AK, Bharagava RN, Thapa KB. Green synthesis of $\mathrm{TiO}_{2}$ nanoparticles using leaf extract of Jatropha curcas L. for photocatalytic degradation of tannery wastewater. Chem Eng J 2018;336:386-96.

54. Hassanien R, Husein DZ, Al-Hakkani MF. Biosynthesis of copper nanoparticles using aqueous Tilia extract: antimicrobial and anticancer activities. Heliyon. 2018:4:e01077.

55. Lakhotia SR, Mukhopadhyay M, Kumari P. Iron oxide (FeO) nanoparticles embedded thin-film nanocomposite nanofiltration (NF) membrane for water treatment. Sep Purif Technol. 2019;211:98-107.

56. Sekar AD, Jayabalan T, Muthukumar H, Chandrasekaran NI, Mohamed SN, Matheswaran M. Enhancing power generation and treatment of dairy waste water in microbial fuel cell using Cu-doped iron oxide nanoparticles decorated anode. Energy. 2019;172:173-80.

57. Gunarani Gl, Raman AB, Kumar JD, Natarajan S, Jegadeesan GB. Biogenic synthesis of Fe and NiFe nanoparticles using Terminalia bellirica extracts for water treatment applications. Mater Lett. 2019;247:90-4.

58. Malhotra S, Jha N, Desai K. A superficial synthesis of selenium nanospheres using wet chemical approach. Int J Nanotechnol Appl. 2014;3:7-14.

59. Ramamurthy C, Sampath KS, Arunkumar P, Kumar MS, Sujatha V, Premkumar $K$, et al. Green synthesis and characterization of selenium nanoparticles and its augmented cytotoxicity with doxorubicin on cancer cells. Bioproc Biosyst Eng. 2013;36:1131-9.

\section{Publisher's Note}

Springer Nature remains neutral with regard to jurisdictional claims in published maps and institutional affiliations.

\section{Ready to submit your research? Choose BMC and benefit from:}

- fast, convenient online submission

- thorough peer review by experienced researchers in your field

- rapid publication on acceptance

- support for research data, including large and complex data types

- gold Open Access which fosters wider collaboration and increased citations

- maximum visibility for your research: over $100 \mathrm{M}$ website views per year

At $\mathrm{BMC}$, research is always in progress.

Learn more biomedcentral.com/submissions 